\title{
Optimization of Microcystin Extraction for Their Subsequent Analysis by HPLC-MS/MS Method in Urban Lake Water
}

\author{
Qu Jiang-qi, Zhang Qing-jing, Jia Cheng-xia, Liu Pan, and Yang Mu
}

\begin{abstract}
This paper represents to propose an effective extraction procedure for traditional toxin determination techniques in urban lake. Efficiency of each extraction solvent as well as other key parameters affecting extraction efficiency including ultrasonication time and extraction $\mathrm{pH}$ were evaluated and optimized. The present study results indicated that $40 \%$ acidified methanol $(\mathrm{pH} \sim 3)$ with sonication $15 \sim 20 \mathrm{~min}$ has been shown to be a rapid and efficient method for the routine analysis of a wide range of microcystins in water samples. Our study also suggested that analytical method based on HPLC-MS/MS with SPE techniques provides a simplified enrichment procedure and rich information for both quantization and identification effective tool for analysis of urban landscape water quality. The development of this method may facilitate the understanding of the best extraction method for the routine analysis of microcystins in water bodies. Moreover, it may be valuable for purification scale.
\end{abstract}

Index Terms-Microcystin, extraction, HPLC-MS/MS, urban landscape water.

\section{INTRODUCTION}

Urban landscape water in China are very often man-made ecosystem. They are very small and shallow. As an essential part of urban ecosystem, urban lake also play an important role in promoting socio-economic development, by regulating climate and providing a good place for recreational [1]-[2]. With increasing anthropogenic activities and excessive inputs of nitrogen and phosphorus to water environments, urban lake waters quality are extremely deteriorated in recent years. As a consequence, the appearance of Cyanobacteria (blue-green algae) can produce microsytins, frequently breakout in highly eutrophication lakes. It is considered to be an important water quality problem, implicating that a serious health problem in water supplies, both for livestock and human health [3]-[5].

Microcystin is the most commonly synthesized toxin produced by toxin producing cyanobacteria species of Microcystis, Aphanizomenon, Anabaena, Planktothrix and Phormidium with around 80 variants characterized to date [6], [7]. In the past two decades, microcystion have been largely explored by a variety of analytical techniques []. Of all the reported methods, ELISA, HPLC and LC-MS are the main

Manuscript received April 25, 2013; revised June 9, 2013. This work was supported by Beijing Academy of Agriculture and Forestry Sciences Funds for Distinguished Young Scientists.(QNJJ201315); Aquaculture water remediation and purification technology research; National Technology System for Conventional Freshwater Fish Industries.

The authors are with Beijing Fisheries Research Institute, Beijing, China (e-mail: quqi20122012@163.com, qingjingzhang2007@yahoo.com.cn). methods for toxin analysis. However, ELISA only gives a summation of microcystin-type toxicity, depending on the antibodies employed in the kits [8], [9]. HPLC is capable of separating the cyanobacteria toxins, but it does not provide an accurate estimation of minor components [10], [11]. Compare to these methods, recent technological developments drive HPLC-MS/MS towards extremely fast analysis times without sacrificing chromatographic efficiency and sensitivity, had been widely applied to detect numerous toxins in water bodies in recent years [12], [13].

Currently, there is a lack of understanding toxicology and risk assessment of urban lake Cyanobacterial toxins. For deeply study urban lake microcystins during algal blooms, optimization of extraction were conducted by HPLC-MS/MS approaches in our study for determination of microcystins from urban lake samples.

\section{MATERIALS AND MethodS}

\section{A. Chemicals}

All the chemicals include HPLC-S grade acetonitrile, HPLC grade methanol and Trifluoroacetic acid (TFA) were purchased from Beijing Chemicals Ltd. Ultra-pure water was prepared on a Milli-Q Synthesis system (Millipore, France). microcystin LR, RR standards were bought from Beijing express Company. Sep-pak ODS cartridge (1000g, 12ml) was manufactured by Tianjin Alega Technologies.

\section{B. Sample Preparation for Microcystins Extraction}

Before the HPLC analyses, all water samples (1 L) were filtered on GF/C filters. Commercially available SPE fibers were purchased from Alega. Each fiber was eluted by $20 \mathrm{ml}$ methanol and pure water $20 \mathrm{ml}$ separately before extraction. To carry out the SPE extraction, water samples were extracted under different conditions in order to determine the optimal condition for microcystins extraction. After SPE procedures, the methanol was evaporated to dryness under nitrogen and was reconstituted in $1 \mathrm{ml}$ methanol for subsequent analysis by HPLC-MS/MS.

\section{HPLC-MS/MS Parameters}

Identification and quantification of microcystins were performed by LC-MS with Dionex Ultimate 3000 (Dionex, USA), an Ultimate $\mathrm{XB}^{-\mathrm{C}_{18}}$ column $(150 \mathrm{~mm} \times 4.6 \mathrm{~mm}, 5 \mu \mathrm{m})$ and a 3200Q TRAP LC/MS/MS Mass system (Aglient, USA). The column oven was set at $30 \mathrm{C}$ with a mobile phase flow of $0.8 \mathrm{ml} / \mathrm{min}$. The mobile phase consisted of CAN and water with $0.1 \%(\mathrm{v} / \mathrm{v})$ formic acid. The injection volume was $10 \mathrm{ml}$. 
The mass spectrometer used was operated in ESI positive mode with a capillary voltage of $5 \mathrm{kV}$ and heated capillary temperature was maintained at $500^{\circ} \mathrm{C}$. Conditions for mass spectrometry are shown in Table I and Fig.1.

TABLE I: MASS SPECTROMETRY PARAMETERS.

\begin{tabular}{llll}
\hline Toxin & Retention time $(\mathrm{min})$ & Precursor ion $\mathrm{m} / \mathrm{z}$ & Product ion $\mathrm{m} / \mathrm{z}$ \\
\hline MC-RR & 5.35 & 519.8 & 135.0 \\
MC-LR & 5.80 & 995.6 & 135.0 \\
\hline
\end{tabular}


Fig. 1. MRM chromatograms of the MC-RR (a) and MC-LR (b) standards.

\section{Optimization Experiment Design}

In this exploratory study, the focus was the extraction efficiency using the SPE technique. First of all, optimize the extraction solvents proportion. The solvents evaluated were water, methanol and acetic acid. In this work, $10 \% \sim 70 \%$ water-methanol solution $+3 \%, 5 \%$ and $7 \%$ acetic acid combinations were designed for optimization. Second, extractions were performed under ultrasonication $(300 \mathrm{~W})$ for: $5,10,15,20,30,40$ and $50 \mathrm{~min}$ for optimization of extraction time. Finally, we study the extraction at different $\mathrm{pH}$ values, ranging from $\mathrm{pH} \sim 1, \mathrm{pH} \sim 3, \mathrm{pH} \sim 5, \mathrm{pH} \sim 7, \mathrm{PH} \sim 9$ and $\mathrm{pH} \sim 11$. Extracts corresponding to each extraction step were performed three times and analyzed separately by HPLC-MS/MS.

\section{RESUlTS AND DisCUSSION}

\section{A. Extraction of Microcystins with Different Solvent Combinations}

As shown in Fig.2, the best extraction efficiencies for MC -LR and MC-RR studied were obtained. The greatest increase in extraction efficiency was observed found in different combines shows that $40 \%$ methanol $+5 \%$ acetic acid, $40 \%$ methanol $+3 \%$ acetic acid and $40 \%$ methanol + $5 \%$ acetic acid extracted $788 \mathrm{ng} / \mathrm{ml}$ for $\mathrm{MC}, 257 \mathrm{ng} / \mathrm{ml}$ for MC- LR and $632 \mathrm{ng} / \mathrm{ml}$ for MC-RR, respectively. Previous results reported that mixtures of methanol and water extracted more efficiently compared to extraction with methanol and water, respectively [14], and acidified methanol led to the higher microcystins yields, since hydrophobic character of microcystins improves as the $\mathrm{pH}$ value decreases [15]. Wei et al. [16] shows that microcystin-LR yield in acidified methanol was twice that obtained in methanol alone. Similar results also obtained in the present study. As Fig. 2 shown, 5\% acidified methanol group extracted higher yields of MC. 3\% acidified methanol group shows that the great efficient extraction solvent for MC-RR. All these results indicated that suitable acidified methanol proportion was the best solvent for the extraction of microcystins. In the present study, we also found $40 \% \sim 50 \%$ mixtures and water seemed to be selected as the most suitable mixture for the extraction of microcystins. Results obtained prior studies were consistent with present results [17-18]. However, results from the extraction experiments were somewhat differ. Barco et al. [19] reported that $80 \%$ aqueous methanol was the most suitable mixture for the extraction of both hydrophobic and hydrophilic microcystins.
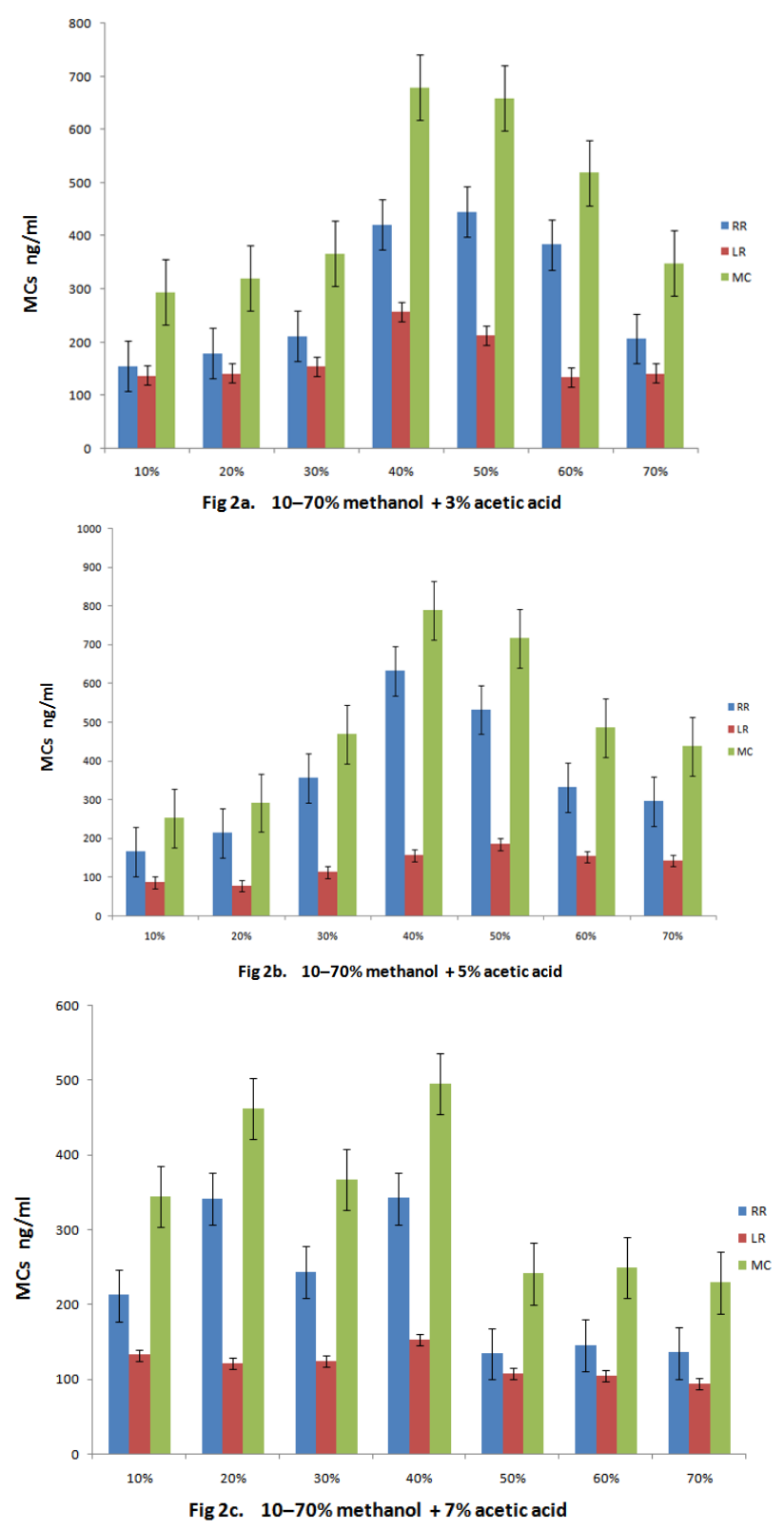

Fig. 2. Different solvent combinations in extraction solution 


\section{B. Extraction of Microcystins with Different Sonication Time}

After the extraction solvent system were chosen and tested as an efficient extraction solution, ultrasonication time was adjusted for optimal toxin extraction. Among seven treatments of different sonication time, no significant increase was observed in microcystin extraction yield over time. Consider short time of analysis involved,15 min was chosen as the extraction time in $40 \%$ methanol $+3 \%$ acetic acid group for MC-LR, and 20min was chosen as the optimum extraction time for toxin extraction in $40 \%$ methanol $+5 \%$ acetic acid group for MC-RR. These results are similar with the previous results reported [18].

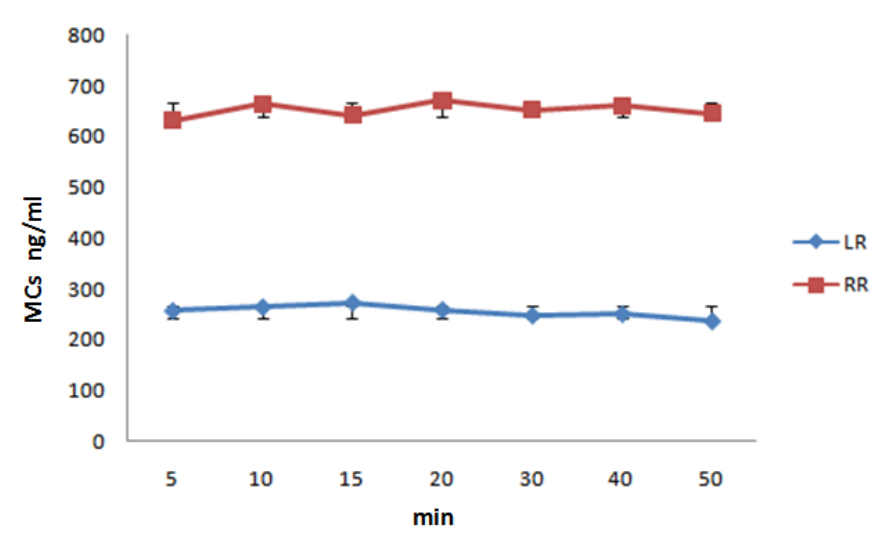

Fig. 3. Extraction MC-RR and MC-LR for different sonication time

\section{Optimization of the Extraction $p H$}

Based on the results above, the best extraction efficiencies for MC-RR and MC-LR studied were studied. As can be observed in Fig.4, when extracting with acidified methanol at $\mathrm{pH} \sim 1$ and $\mathrm{pH} \sim 3$, both MC-RR and MC-LR obtained greatest yields of extraction efficiency. Some studies have been reported that suitable toxin extractions from soils and sediment is a range of $\mathrm{pH}$ values from 3 to 7 , and bloom samples optimum extraction $\mathrm{pH}$ was chosen $\mathrm{pH} 2$ [19], [20]. It is suggesting that a slightly acidic extraction solvent system is more suitable for microcystins extraction. However, microcystins would degrade at very high acidic conditions ( $\mathrm{pH} \sim 1$ ), $\mathrm{pH} \sim 3$ was chosen as the optimum extraction $\mathrm{pH}$ in the present work.

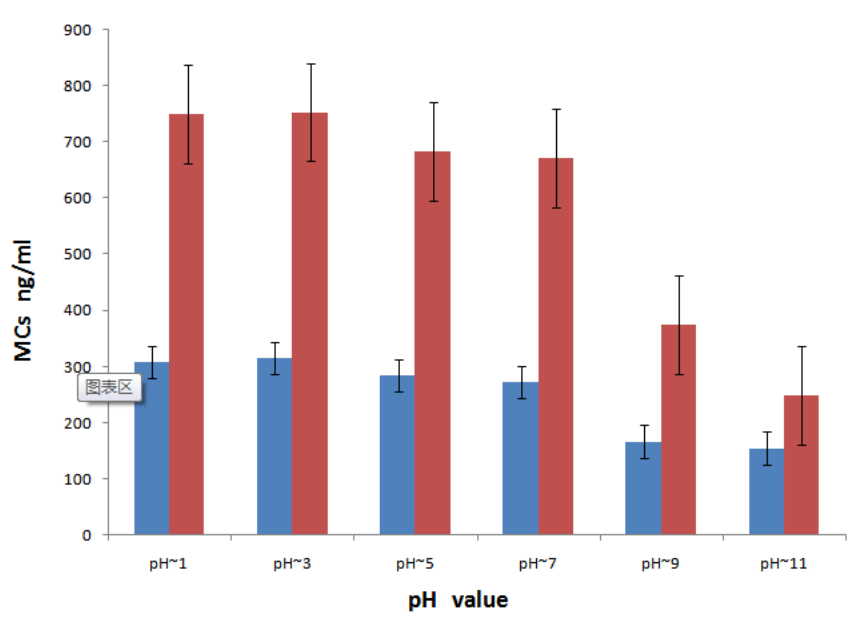

Fig. 4. Extraction MC-RR and MC-LR for different $\mathrm{pH}$ value

The SPE technique have been demonstrated to be a simple, reliable, and simplifies the enrichment process, eliminates the use of organic solvents, and reduces the cost of disposal. In this work, the developed technique of SPE with HPLC -MS/MS provides a simplified enrichment procedure and rich information for both quantization and identification.

Based on the results above, an optimal extraction procedure is schematically proposed in Fig. 5.

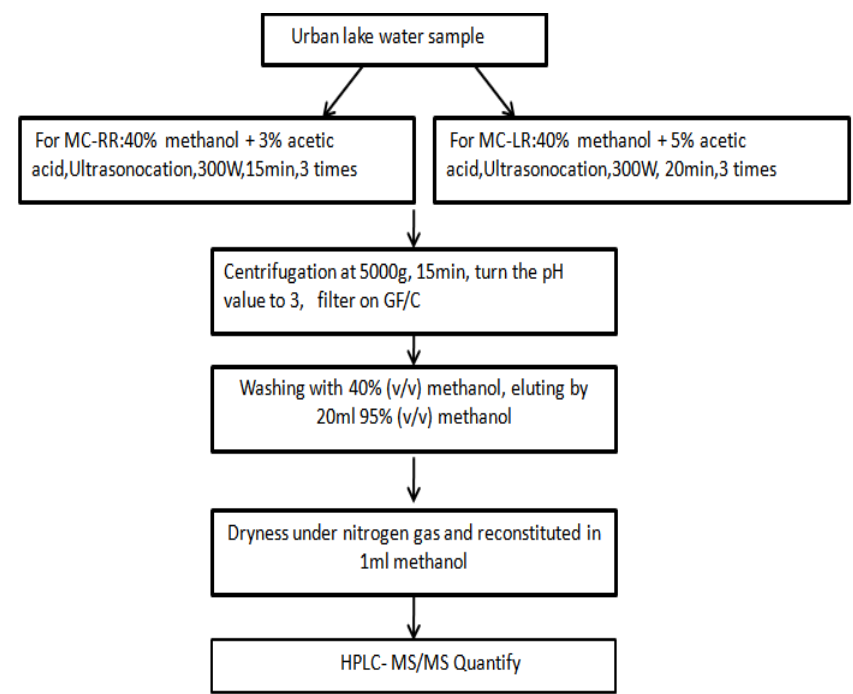

Fig. 5. A schematic diagram of the analytical procedure for microcystins in urban lake

\section{CONCLUSION}

This study focuses on the occurrence of cyanobacterial toxins of urban landscape water in china. These toxins are well known to produce several metabolites significant from the public health perspective of acute exposure. Due to their hazard to human health, extraction of microcystin variants is required to characterize and quantify all microcystins present in water bodies. In the present study, a wide range of extraction solvents were evaluated over a wide range of $\mathrm{pH}$ and extraction times to optimize an effective extraction procedure for the analysis of microcystins in urban lake. The results show that $40 \%$ acidified methanol $(\mathrm{pH} 3)$ with sonication $15 \sim 20 \mathrm{~min}$ has been shown to be a rapid and efficient method for the routine analysis of a wide range of microcystins in urban lake. Furthermore, the method also can be applied to the analysis of intracellular microcystins in water bloom samples, contained in cells usually trapped on $\mathrm{GF} / \mathrm{C}$ filters.

\section{REFERENCES}

[1] S. Burmila, T. C. Danielb, and J. D. Hetherington, "Human values and perceptions of water in arid landscape," Landscape and Urban Planning, vol. 44, pp. 99-109, 1999.

[2] M. D. Velardea, G. Fryb, and M. Tveit, "Health effects of viewing landscapes - Landscape types in environmental psychology," Urban Forestry and Urban Greening, vol. 6, pp. 199-212, 2007.

[3] C. S. Bozarth, A. D. Schwartz and J. W. Shepardson, "Population turnover in a Microcystis bloom results in predominantly nontoxigenic variants late in the season," Appl Environ Microbiol, vol. 76, pp. 5207-5213, 2010.

[4] P. R. Hawkins, N. R. Chandrasena, G. J. Jones et al. "Isolation and toxicity of Cylindrospermopsis raciborskii from an ornamental lake," Toxicon, vol. 35, pp. 341-346, 1997.

[5] A. Fristachi and J. L. Sinclair, "Occurrence of cyanobacterial harmful algal blooms workgroup report. In: Hudnell, K.H. (Ed.), 
Cyanobacterial Harmful Algal Blooms: State of the Science and Research Needs," Springer, pp. 45-103, 2008.

[6] A. R. Humpage and I. R. Falconer, "Oral toxicity of the cyanobacterial toxin cylindrospermopsin in male Swiss albino mice: determination of no observed adverse effect level for deriving a drinking water guideline value," Environ. Toxicol, vol.18, pp. 94-103, 2003.

[7] G. A. Codd, J. Lindsay, F. M. Young, and L. F. Morrison, "Harmful Cyanobacteria: from mass mortalities to management measures". In: J. Huisman, H. C. P., Matthijs, P. M. Visser, (Eds.), Harmful Cyanobacteria, Springer, pp. 1 - 23, 2005.

[8] J. S. Metcalf, S. G. Bell, and G. A. Codd. "Colorimetric immuno-protein phosphatase inhibition assay for specific detection of microcystins and nodularins of cyanobacteria," Appl. Environ. Microbiol, vol 67, pp 904-909, 2001.

[9] C. Rivasseau, P. Racaud, A. Deguin, and M. C. Hennion. "Evaluation of an ELISA kit for the monitoring of microcystins (cyanobacterial toxins) in water and algae environmental samples," Environ. Sci. Technol. vol. 33, pp. 1520-1527, 1999.

[10] J. Rapala, K. Erkomaa, J. Kukkonen, K. Sivonen, and K. Lahti "Detection of microcystins with protein phosphate inhibition assay, high-performance liquid chromatography-UV detection and enzyme-linked immunosorbent assay comparison of methods," Anal.Chim. Acta, vol. 466, pp. 213-31, 2002.

[11] H. S. Lee, C. K. Jeong, H. M. Lee, S. J. Choi, K. S. Do, K. Kim, and Y. H. Kim, "On-line trace enrichment for the simultaneous determination of microcystins in aqueous samples using high-performance liquid chromatography with diode-array detection," Chromatogr, vol. 848, pp. 179-84, 1999.

[12] L. Zhang, X. Ping, and Z. Yang. "Determination of microcystin-LR in surface water using high performance liquid chromatography/tandem electrospray ionization mass detector,” Talanta, vol. 62, pp. 193-200, 2004.

[13] J. Osswald and A. Vasconcelos V. "Toxicology and detection methods of the alkaloid neurotoxin produced by cyanobacteria, anatoxin-a," Environ. Int., vol. 33, pp. 1070-1089, 2007.

[14] W. Mathys and B. Surholt, "Analysis of microcystins in freshwater samples using high performance liquid chromatography and an enzyme-linked immunosorbent assay," International Journal of Hygiene and Environmental Health, vol. 207, pp. 601-605, 2005.

[15] L. A Lawton, C. Edwards, and G. A. Codd, "Extraction and high-performance liquid chromatographic method for the determination of microcystins in raw and treated waters," The Analyst, vol. 119, pp. 1525-1530, 1994

[16] W. Chen, L. Li a, N. Q. Gan, and L. Song, "Optimization of an effective extraction procedure for the analysis of microcystins in soils and lake sediments," Environmental Pollution, vol. 143, pp. 241-246, 2006.

[17] W. M. Niu, F. G. Xiao, and W. J. Dai. "Simultaneous Determination of five Microcystins in Water by high Performance Liquid Chromatography-tandem Mass Spectrometry," Journal of Anhui Agri. Sci., vol. 36, pp. 12554-12556, 2008. (in Chinese)
[18] H. Yan, G. Pan, and M. M. Zhang, "Study onthe extraction and purif ication of microcystins," Acta Scientiae Circumstantiae, vol. 24, pp. 355-359, 2004. (in Chinese).

[19] M. Barco, L. A. Lawton, and J. Rivera, J. “Optimization of intracellular microcystin extraction for their subsequent analysis by high-performance liquid chromatography," Journal of Chromatography, vol. 1074, pp. 23-30, 2005.

[20] L. Peng, W. Chen, and L. R. Song, "Study on extraction methods of intracellur microcystins," Acta Hydrobiologica Sinica, vol. 35, pp. 708-712, 2011.

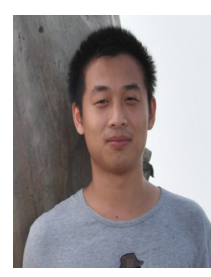

Qu Jiang-qi was born in Shenyang which is the biggest city in the northeast of china. In 2011 he got his Master degree in Nanjing Agriculture University which is widely considered one of the China's best agriculture schools. During his study periods, he got a lot of knowledge about aquaculture and hydrobiology.

After he got his Master degree he joined Beijing Fisheries Research Institute in 2011.There he is involved in various research projects related to water environmental protection technology. So far, he has published five articles such as "The Structure of Phytoplankton Community and Ecological Evaluation of Water Quality of Two Landscape Lakes in Beijing".

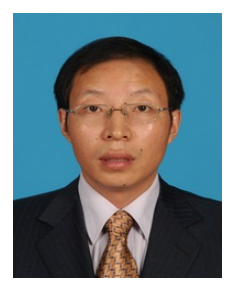

Zhang Qing-jing was born in Pingchang county, Sichuan, China, in 1974. Bachelor's degree master degree and Ph. D were gained in Northeast Forestry University in 1998, Dalian Ocean University in 2001, and China Agricultural University in 2012, respectively. The major field of study is of knowledge about ecology, aquaculture and hydrobiology during study periods.

After gaining his Master degree in 2001, he joined Beijing Fisheries Research Institute. There he is involved in various research projects related to freshwater fishery, aquaculture, water ecology and water environmental protection technology, etc. So far, he has published more than thirty papers such as "Relationships between copepods and Eriocheir sinensis larvae in ecological breeding ponds.", "A comparative study on effects of three freshwater algae species on rotifer Brachionus calyciflorus cultivation", and "The Structure of Phytoplankton Community and Ecological Evaluation of Water Quality of Two Landscape Lakes in Beijing". At present, his research interests focus mainly on fishery ecology and water environmental conservation.

Dr. Zhang is director of Fisheries Ecology and Environmental Conservation Lab, Beijing fisheries Research Institute, China, membership of Chinese Society of Scientific Fisheries, and member of the council of Beijing Society of Scientific Fisheries. 